\title{
Efficient Modification on PLLA by Ozone Treatment for Biomedical Applications
}

\author{
Ming-Hua Ho, Juin-Jay Lee, Shu-Chin Fan, Da-Ming Wang, \\ Lein-Tuan Hou, Hsyue-Jen Hsieh, Juin-Yih Lai*
}

RGDS (Arg-Gly-Asp-Ser) is immobilized on poly(I-lactic acid) (PLLA) with ozone oxidation and the addition of an intermediate reactant, acryl succinimide (ASI) to promote the grafting efficiency. A DPPH (2,2-di(4-tert-octylphenyl)-1-picrylhydrazyl) assay has revealed that the peroxide concentration can be controlled by adjusting the ozone treatment time. The immobilization of ASI is verified by elemental analysis. The peptide concentrations are in the effective order, as shown by means of high performance liquid chromatography (HPLC), and the grafting efficiency is proven to be relatively high compared with the previous studies. The culture of rat osteosarcoma 17/2.8 (ROS), osteoblastic-like cells, demonstrates that the grafting of RGDS can enhance the attachment and osteogenesis of ROS cells on PLLA. With the addition of ASI, the cultured ROS cells express normal function in proliferation and mineralization. From in vivo experiments, ASI immobilized on the surface is shown to be biocompatible. These results lead to the conclusion that the ozone treatment with the intermediate reactant ASI is an efficient, biocompatible, and easily controllable procedure to modify PLLA. Furthermore, the immobilization of RGDS in significant amounts following the ozone oxidation could further promote the biocompatibility and the osteoinduction of PLLA.

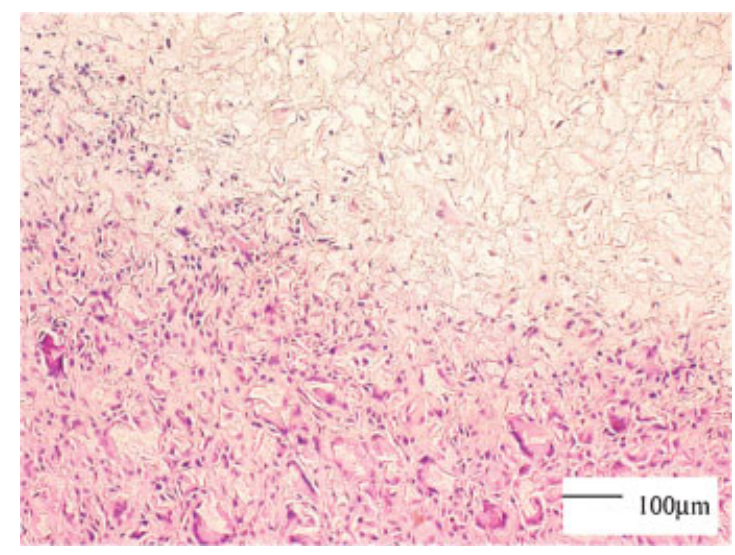

M.-H. Ho, S.-C. Fan, J.-Y. Lai

R\&D Center of Membrane Technology and Department of Chemical Engineering, Chung Yuan University, Chungli,

Taiwan ROC

Fax: +886-2-27376644; E-mail: mhho@mail.ntust.edu.tw

M.-H. Ho, J.-J. Lee

Department of Chemical Engineering, National Taiwan University of Science and Technology, Taipei, Taiwan ROC

D.-M. Wang

Department of Chemical Engineering, National Taiwan University, Taipei, Taiwan ROC

D.-M. Wang

Institute of Polymer Science and Engineering, National Taiwan University, Taipei, Taiwan ROC

L.-T. Hou, H.-J. Hsieh

Department of Periodontology, School of Dentistry, National

Taiwan University, Taipei, Taiwan ROC

\section{Introduction}

Many aliphatic types of polyesters have been extensively used for biomedical applications. ${ }^{[1-5]}$ Nevertheless, many kinds of polyesters show drawbacks that result from their low bio-affinity. The difference in physicochemical properties between hydrophobic polyesters and hydrophilic bioactive signals has a profound consequence on biomedical applications. ${ }^{[6-8]}$ In order to achieve a higher attached cell density and to promote neovascularization when the biomedical materials are implanted, many studies have been reported to modify these biodegradable polymers. ${ }^{[9-13]}$ One of the approaches is the introduction of functional groups onto polymer chains. ${ }^{[11-13]}$ Not only can the introduction of functional groups increase the 
biocompatibility of the polyester, it also provides active sites to react with the other biomolecules, like peptides or proteins.

Functional groups can be grafted onto the polyesters in a number of ways. ${ }^{[14-20]}$ Ozone activation can create sites that possess high chemical activity on a material's surface, and a modification or further graft can thus be carried out. On the surface of polymers, the ozone oxidation can produce peroxides and hydroperoxides with free radicals, and the following immobilization of functional molecules can be performed under thermal or initiator induction. ${ }^{[13,20]}$ With the modification process, the bulk properties of polymers can be preserved after ozone treatment, which indicates that the mechanical strength or biodegradability may not be significantly varied as a result of the modification.

However, the grafting efficiency of ozone treatment on poly(L-lactic acid) (PLLA) is usually lower than $5 \%^{[13,20,21]}$ and still too low to be commercialized. A grafting efficiency higher than $20 \%$ is almost impossible, even with very complicated reaction procedures. It means that most of biosignals used for the modification process would be wasted, which is a critical problem especially when the biosignal is expensive or rare, such as some growth factors. In order to increase the efficiency without complicated procedures, the processes of ozone treatment in this research was modified by the addition of an intermediate reactant, acryl succinimide (ASI). In the modification of filtration membranes with ozonation, ${ }^{[22,23]}$ the addition of ASI has been proven to efficiently increase the grafted amount of monomers. Hence, ASI is first used in this research to modify PLLA, which is supposed to improve the grafting efficiency in ozone activation. After ASI grafting, the immobilization of RGDS (Arg-Gly-Asp-Ser), which is associated with cell attachment and cell differentiation, ${ }^{[24]}$ onto PLLA was carried out. The potential for further linkage between PLLA-ASI and biosignals, such as peptides or proteins, was investigated by RGDS immobilization. From the analysis of the RGDS immobilization, the effect that results from the addition of ASI can be verified by comparing to previous studies. Meanwhile, the commercialized potential of this modification process is also evaluated from this analysis. For biomedical applications in the future, the biocompatibility of PLLA-ASI-RGDS is established by in vitro and in vivo tests in this paper.

\section{Experimental Part}

\section{Materials}

PLLA (MW $=85$ 000-160 000), RGDS, ASI, 1,4-dioxane, and phosphate buffered saline (PBS) were purchased from Sigma. (2,2-Di(4-tert-octylphenyl)-1-picrylhydrazyl) (DPPH) and $\mathrm{HCl}$ were obtained from Aldrich, 1-methyl-2-pyrrolidinone (NMP) and isopropyl alcohol (IPA) were from Tedia Company, and ethanol was from Seoul Chem. Ind. All the solvents used were of analytical quality. Distilled and deionized water was used throughout this study. For cell culture, $\alpha$-minimum essential medium $(\alpha M E M)$, sodium $\beta$-glycerophosphate, ascorbic acid, and dexamethasone were purchased from Sigma, and fetal bovine serum (FBS), penicillin-streptomycin-amphotercin and trypsin-EDTA solution were purchased from GIBCO BRL. The reagents for the measurement of ALPase and von Kossa staining, which include sodium carbonate, $p$-nitrophenylphosphate, $\mathrm{MgCl}_{2}$, ALPase (alkaline phosphatase), DNA quantification kit, and silver nitrate, were purchased from Sigma.

\section{Preparation of PLLA Film and Scaffolds}

PLLA was dissolved in dioxane to form a $3 \mathrm{wt}$.-\% polymer solution. The solution was used to prepare PLLA films and scaffolds. To prepare dense films, the solution was coated onto a petri dish and then dried at $50^{\circ} \mathrm{C}$. The film for cell attachment was circular with a diameter of $6 \mathrm{~cm}$. Porous PLLA scaffolds were prepared by the so-called freeze-extraction method, with details described in our previous work. ${ }^{[25]}$ The PLLA solution was placed in a petri dish and frozen at $-20^{\circ} \mathrm{C}$. The frozen PLLA solution was immersed in an aqueous ethanol solution of 50 vol. $\%$ at $-20^{\circ} \mathrm{C}$ to allow the extraction between ethanol and dioxane. The gelled solution was dried at room temperature and porous PLLA scaffolds were obtained.

\section{Ozone Treatment of PLLA}

The PLLA film or scaffold was suspended in the IPA solution, where a stream of $\mathrm{O}_{3} / \mathrm{O}_{2}$ mixture was bubbled through continuously. The $\mathrm{O}_{3}$ was generated from the ozone generator (Ray-Yi Ozone Group OG-10PWA, Taiwan) with an oxygen flow rate of $6 \mathrm{~L} \cdot \mathrm{min}^{-1}$. The solution with polymer suspension was treated with ozone for $15,30,45$, and $60 \mathrm{~min}$ at $25^{\circ} \mathrm{C}$, and then cooled in an ice bath.

\section{Determination of Peroxide Concentration}

For the determination of peroxide concentration, ozone-treated PLLA (100 mg) was immersed into $10 \mathrm{~mL}$ of dry NMP that contained 10-15 mg of DPPH. The solution was saturated with nitrogen for $60 \mathrm{~min}$. The PLLA samples were dissolved in NMP in an oil bath at $120^{\circ} \mathrm{C}$ and the nitrogen gas passed through the solution for $30 \mathrm{~min}$. After that, the solution was cooled in an ice bath for $30 \mathrm{~min}$ immediately, and poured into $90 \mathrm{~mL}$ of IPA. The residual DPPH concentration was then determined from the absorption intensity at $520 \mathrm{~nm}$ by UV-visible absorption spectroscopy (Varian DMS300, USA). The concentration of peroxides in moles per gram on the PLLA was determined by the DPPH assay (see Equation (1)): ${ }^{[26]}$

$$
\begin{aligned}
& \text { [peroxides }] \\
& \quad=\left[\left(C_{0}-C\right) \times 100\right] /(2 \times 1000 \times 394.33 \times m)
\end{aligned}
$$


where $m$ denotes the weight of the ozone-treated PLLA sample in grams, and $C_{0}$ and $C$ are the initial and final DPPH concentrations in $\mathrm{g} \cdot \mathrm{L}^{-1}$, respectively.

\section{Grafting of ASI and RGDS onto the Ozone-Treated PLLA}

The graft of ASI onto PLLA was performed by thermal induction. ASI (0.5 g), PLLA (1 g, films or scaffolds), and $20 \mathrm{~mL}$ of dry NMP were introduced into a two-necked flask. The flask was saturated with nitrogen gas for $1 \mathrm{~h}$ under stirring, and then placed into an oil bath at $60^{\circ} \mathrm{C}$. After $12 \mathrm{~h}$, the flask was cooled in an ice bath and the PLLA-ASI was rinsed several times with ethanol. For the immobilization of RGDS, the PLLA-ASI was immersed into the degassed RGDS solution ( $1 \mathrm{mg}$ RGDS $/ 40 \mathrm{~mL} \mathrm{H}_{2} \mathrm{O}$ ) at $4{ }^{\circ} \mathrm{C}$ for $2 \mathrm{~d}$, and then washed with PBS buffer for $2 \mathrm{~d}$. The treatment conditions for each sample are described in Table 1.

\section{Contact Angle Measurement}

To determine the change in the hydrophilicity of PLLA after the modification, contact angles of PLLA films were measured by using an inverted microscope (model IX70, Olympus, Japan) and a CCD camera (model VK-c370, Hitachi, Japan). A drop of water (5 $\mu \mathrm{L}$ ) was placed on the PLLA films, and the image of the water droplet was immediately taken and analyzed for contact angles.

\section{Elemental Analysis}

Elemental analyses of the modified and unmodified PLLA were investigated using an Elemental Analyzer (Heraeus vario III-NCSH, Germany). The bulk grafting concentration of ASI was calculated by Equation (2):

$$
([\mathrm{HSI}] /[\mathrm{PLLA}])_{\text {bulk }}=[\mathrm{N}] /([\mathrm{C}]-7[\mathrm{~N}])
$$

Table 1. Preparation conditions for modified PLLA by ozone treatment.

\begin{tabular}{lcccc}
\hline Sample code & $\begin{array}{c}\text { Ozone treatment } \\
\text { time }\end{array}$ & & ASI & RGDS \\
\cline { 2 - 3 } \cline { 5 - 5 } & min & & g & mg \\
\hline PLLA & 0 & & 0 & 0 \\
PLLA-15ASI & 15 & & 0.5 & 0 \\
PLLA-30ASI & 30 & & 0.5 & 0 \\
PLLA-45ASI & 45 & & 0.5 & 0 \\
PLLA-15ASI-RGDS & 15 & & 0.5 & 1 \\
PLLA-30ASI-RGDS & 30 & 0.5 & 1 \\
PLLA-45ASI-RGDS & 45 & 0.5 & 1
\end{tabular}

\section{Amino Acid Analysis}

Samples were mixed with $2 \mathrm{~mL}$ of a $12 \mathrm{~N} \mathrm{HCl}$ to hydrolyze the grafted RGDS into individual amino acids. ${ }^{[26]}$ The solutions were placed in glass tubes, which were then sealed under vacuum. The hydrolysis was performed at $120^{\circ} \mathrm{C}$ for $24 \mathrm{~h}$ and the hydrolyzed mixture was further vacuum dried, PITC derived, and re-suspended in $40 \mathrm{~mL}$ of $2 \mathrm{~m} \mathrm{NaOH}$ aliquots. The hydrolyzed samples were analyzed with a Pico-Tag HPLC column (Waters, USA), and the results were obtained based on the results of Amino Acid Standard H (Pierce).

\section{Culture of ROS Cells with PLLA Films}

ROS cells, originally isolated from a rat osteosarcoma, were cultured in $\alpha \mathrm{MEM}$, supplemented with $10 \% \mathrm{FBS}$ and $100 \mathrm{U} \cdot \mathrm{mL}^{-1}$ of penicillin-streptomycin-amphotercin, at $37^{\circ} \mathrm{C}$ in $5 \% \mathrm{CO}_{2}$. The medium with suspended ROS cells $\left(5 \times 10^{4}\right.$ cells $\left.\cdot \mathrm{mL}^{-1}\right)$ were added into petri dishes on which the modified or unmodified PLLA films were placed. After incubation for a certain period, the dishes were rinsed with PBS buffer and the number of the attached cells was then counted under a microscope. For the in vitro mineralization, ROS cells were cultured for $7 \mathrm{~d}$ to the confluent state and then the medium was changed to a mineralization-inducing medium. ${ }^{[26,27]}$ After the culture with mineralization-inducing medium for $10 \mathrm{~d}$, the osteoblastic marker of calcium deposition was analyzed.

\section{Analysis of ALPase (Alkaline Phosphatase) Activity}

The ROS cells cultured for 4 and $7 \mathrm{~d}$ on PLLA films were dissolved with $0.05 \mathrm{~N} \mathrm{NaOH}$. The solutions of cell layers were used as an enzyme solution for the determination of ALPase activity. ${ }^{[27]}$ The reaction was continued for $30 \mathrm{~min}$, and the absorption was then measured at $405 \mathrm{~nm}$ with a spectrophotometer (Beckman-DU640, USA). Cellular DNA was measured by the DNA quantification kit.

\section{Histochemical Staining: von Kossa Staining}

The films with suspected mineralized cells were stained with a silver nitrate solution and counterstained with Nuclear Fast Red solution. ${ }^{[26,27]}$ The stained samples were then examined with microscopy (model IX70, Olympus, Japan).

\section{In Vivo Experiments}

The PLLA scaffolds were washed with distilled water for $30 \mathrm{~min}$ and with 70 vol.-\% ethanol for $2 \mathrm{~h}$. The scaffolds were then immersed in physiological solution. Male Wistar rats, approximately 4 months old, were used and anesthetized. The scaffolds were implanted subcutaneously by $1 \mathrm{~cm}$ incisions. The rats were observed every week after the implantation, until the rats were killed. The tissue samples were removed and fixed, dehydrated, and embedded in paraffin. Hematoxylin and eosin staining was carried out on the sections, which were then observed by 
microscopy (model IX70, Olympus, Japan). Meanwhile, the analysis for the completeness of implanted scaffolds was performed.

\section{Results and Discussion}

\section{Characterization of PLLA-ASI Copolymers}

The peroxide contents of the ozone-treated PLLA were determined by the DPPH assay. ${ }^{[27]}$ The results are described in Table 2, and show that the peroxide concentration on PLLA significantly increases with time when the time for treatment increases from 0 to $30 \mathrm{~min}$. After $45 \mathrm{~min}$, the amount of generated peroxides reaches a plateau. Accordingly, the most efficient time for ozonation lies between 30 and $45 \mathrm{~min}$ when the flow rate is $6 \mathrm{~L} \cdot \mathrm{min}^{-1}$

Degradation of the polymer would cause failure in mechanical strength, and ozone treatment is also a possible reason for degradation. Significant degradation is observed by a decrease in intrinsic viscosity of the polymer solution. ${ }^{[23,24,28]}$ The intrinsic viscosity was thus measured as an indication of possible polymer chain scission. The data in Table 2 reveal that the intrinsic viscosity of PLLA does not vary significantly with time, and remains similar to that of the unmodified PLLA. Other modification processes for PLLA, such as partial hydrolysis, often cause serious damage to the polymer chain, which results in the failure in mechanical strength. Table 2 suggests that PLLA would not be degraded significantly with ozone treatment in this study, and the ozone treatment process in this research is indeed suitable for the modification of PLLA without significant loss of mechanical strength.

The change in hydrophilicity of PLLA as a result of ozone modification was determined by measuring the contact angles of water. As shown in Table 2, the water contact angles of PLLA decrease slightly with ASI grafting. The results indicate a slight increase in hydrophilicity of the

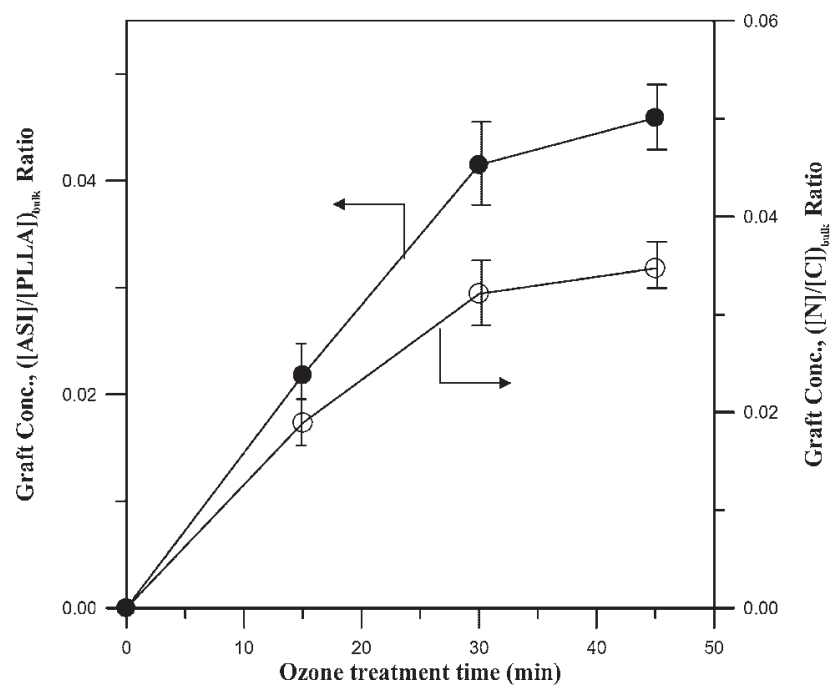

Figure 1. Effect of ozone treatment time on the bulk graft concentration of PLLA-ASI copolymer $(n \geq 3)$.

PLLA-ASI film. The increase may stem from the introduction of a hydrophilic group, ASI, by the ozone treatment.

The immobilization of ASI was verified by elemental analysis, by which the molar ratio of ([ASI]/[PLLA]) bulk could be determined from the $[\mathrm{N}]_{\text {bulk }}$ and $[\mathrm{C}]_{\text {bulk }}$. Because there are no nitrogen atoms in pristine PLLA, the N/C ratio of the unmodified PLLA should be zero. Figure 1 confirms that the ratio of N/C is almost zero for PLLA without ozone treatment. Figure 1 also clearly shows that nitrogen atoms are found on PLLA after reacting with ASI. The results imply that ASI is successfully immobilized on the PLLA as it is the only possible source of nitrogen atoms. Figure 1 also reveals the effect of ozone treatment time on the bulk concentration of the grafted ASI. With a flow rate of $6 \mathrm{~L} \cdot \mathrm{min}^{-1}$, the molar ratio ([ASI]/[PLLA]) bulk initially increases with the ozone treatment time, and reaches a saturated state after 30-45 min. The outcomes are completely identical with the change in peroxide concentration revealed from Table 2 .

Table 2. Peroxides content, intrinsic and water contact angle of pristine and ozone-treated PLLA $(n=4)$. Feed solution/temperature: deionized water $/ 25^{\circ} \mathrm{C}$.

\begin{tabular}{lccr}
\hline Sample code & Peroxide content & $\left.{ }^{*}\right]^{\text {a) }}$ & Water contact angle \\
\cline { 2 - 4 } & mol $\cdot($ g of polymer) & deg. \\
\hline 0 & 0 & $0.624 \pm 0.107$ & $81.4 \pm 2.6$ \\
PLLA-15ASI & $1.91 \times 10^{-6} \pm 6.28 \times 10^{-7}$ & $0.563 \pm 0.045$ & $79.1 \pm 2.9$ \\
PLLA-30ASI & $1.42 \times 10^{-5} \pm 7.73 \times 10^{-6}$ & $0.622 \pm 0.069$ & $77.9 \pm 1.8$ \\
PLLA-45ASI & $1.60 \times 10^{-5} \pm 9.02 \times 10^{-6}$ & $0.607 \pm 0.082$ & $74.7 \pm 3.0$
\end{tabular}

a) Intrinsic viscosity at $20^{\circ} \mathrm{C}$ in dichloromethane. 
Table 3. The amounts of immobilized RGDS per unit mass of PLLA copolymer.

\begin{tabular}{lcr}
\hline Copolymer & mole RGDS/g PLLA & mole RGDS/cm ${ }^{2}$ PLLA \\
\hline PLLA-45ASI & 0 & 0 \\
PLLA-15ASI-RGDS & $4.08 \times 10^{-8} \pm 2.28 \times 10^{-8}$ & $1.04 \times 10^{-10} \pm 5.85 \times 10^{-11}$ \\
PLLA-30ASI-RGDS & $1.20 \times 10^{-7} \pm 7.01 \times 10^{-8}$ & $3.07 \times 10^{-10} \pm 1.82 \times 10^{-10}$ \\
PLLA-45ASI-RGDS & $2.01 \times 10^{-7} \pm 8.64 \times 10^{-8}$ & $5.15 \times 10^{-10} \pm 2.22 \times 10^{-10}$
\end{tabular}

\section{The Effect of Ozone Treatment on the Peptide Immobilization of PLLA Copolymer}

Quantitative analysis of immobilized RGDS was carried out by HPLC. The RGDS was immobilized onto PLLA by immediately immersing the PLLA-ASI films into an RGDS aqueous solution after ozone activation. The succinimide groups of the PLLA-ASI copolymer can react with the $N$-terminal $\alpha$-amino group of RGDS to form amide bonds under thermal induction. Table 3 shows the effect of ozone treatment time on the amount of immobilized RGDS. With longer time for ozone treatment, more RGDS is immobilized onto the PLLA. This result is reasonable because there is more ASI bound to the PLLA as the treatment time increases, which provides active sites to react with RGDS. According to previous studies, ${ }^{[29,30]}$ a surface density of $1 \times 10^{-12} \mathrm{~mol} \cdot \mathrm{cm}^{-2}$ for RGDS on the substrate's surface was sufficient to promote the adhesion of rat calvaria osteoblast-like (ROC) cells. It is acknowledged that not all of the RGDS detected with HPLC is available for cell adhesion because of steric hindrance and the like. How-

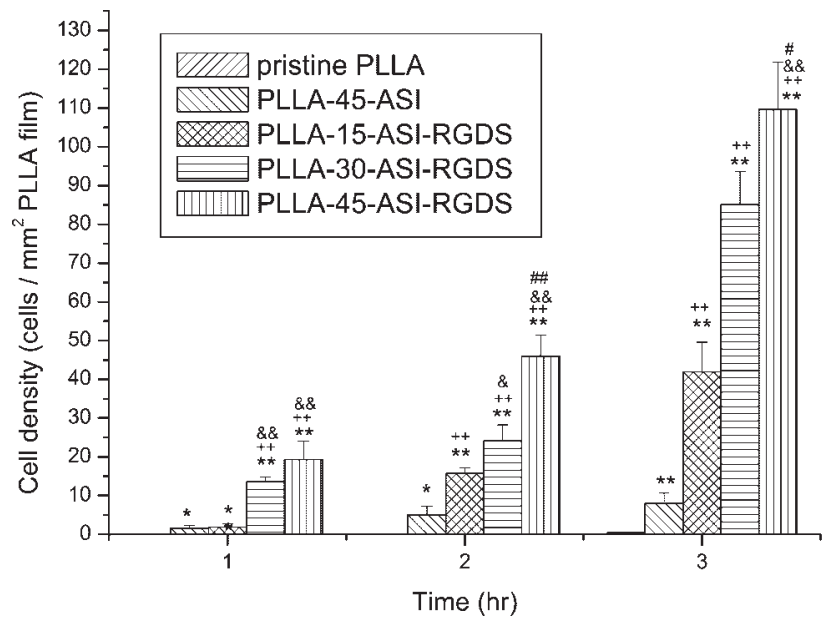

Figure 2. Densities of ROS cells attached on PLLA, PLLA-ASI, and PLLA-ASI-RGDS films. Significance ( $t$-test) is indicated: ${ }^{*} p<0.05$, ${ }^{* *} p<0.01$ compared with pristine PLLA films; ${ }^{+} p<0.05$, ${ }^{++} p<0.01$ compared with PLLA-45ASI films; $\& p<0.05$, $\& \& p<0.01$ compared with PLLA-15ASI-RGDS films; ${ }^{*} p<0.05$, \#\# $p<0.01$ compared with PLLA-3OASI-RGDS films. The above comparisons are for the same culture time $(n=4)$. ever, the amount of RGDS immobilized onto PLLA in this study should be effective enough to enhance cell adhesion.

Compared with previous research devoted to the modification of PLLA, the ozone oxidation is superior in many ways. The ozone modification proposed in this research is much easier, more energy saving, and less time consuming than synthesizing a new copolymer composed of PLA, such as poly(L-lysine) (PLL)-PLA ${ }^{[31]}$ and poly(ethylene glycol) (PEG)-PLA. ${ }^{[32]}$ The bulk properties of PLLA are not significantly changed with the ozone treatment process proposed in this study. Moreover, the graft efficiency of RGDS by ozone treatment in this study is about $22 \%$, which is obviously higher than other processes, such as ozonation and plasma activation, applied to the graft of RGD onto PLLA. ${ }^{[23,33-35]}$ In comparison specifically to the RGDS immobilization with plasma treatment on PLLA, ${ }^{[26]}$ the grafting amount per unit surface area in this study is

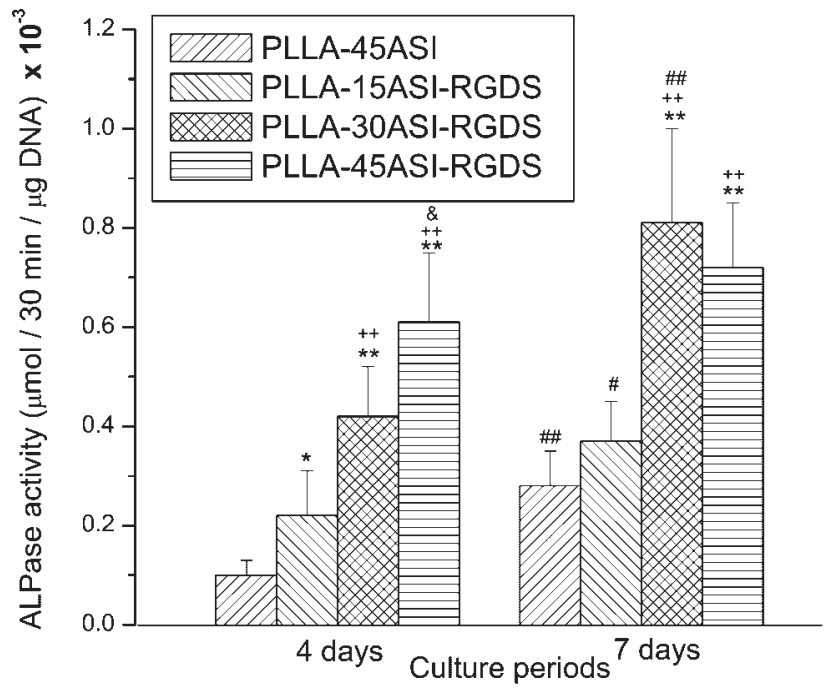

Figure 3. Time dependent changes of ALPase activity in ROS cells cultured with PLLA-45ASI, PLLA-15ASI-RGDS, PLLA-30ASI-RGDS, and PLLA-45ASI-RGDS films. Significance (t-test) is indicated: ${ }^{*} p<0.05,{ }^{* *} p<0.01$ compared with PLLA-45ASI films for the same culture time; ${ }^{+} p<0.05,{ }^{++} p<0.01$ compared with PLLA-15ASIRGDS films for the same culture time; ${ }^{\&} p<0.05,{ }^{\& \&} p<0.01$ compared with PLLA-30ASI-RGDS films for the same culture time; ${ }^{\#} p<0.05,{ }^{\# \#} p<0.01$ compared with the PLLA films with the same modification for the different culture times $(n=5)$. 
increased 25 times when the same amount of RGDS is used in the modification process. It can be concluded that the immobilization of RGDS on PLLA by ozone treatment is effective with easier procedures and is less consuming by the procedures proposed in this research. The novel process described in this study is a promising approach for the modification of PLLA or other biomaterials.

\section{The Effect of Grafted RGDS on Cell Culture}

The numbers of the attached ROS cells at various culture times are described in Figure 2, which shows that the cell affinity of PLLA is strongly improved after ASI and RGDS immobilization. It has been reported that the affinity between cell and pristine PLLA film is poor because of its hydrophobicity. ${ }^{[36]}$ After the immobilization of ASI and RGDS, the cell affinity of PLLA may be improved with the promotion in the hydrophilicity of PLLA. The inference is confirmed by the results that the number of attached cells on the PLLA-45ASI films is higher than that on the pristine PLLA films. However, comparing the cell attachment onto PLLA-ASI films with that onto PLLA-ASI-RGDS films, there are obviously more cells on the PLLA films with RGDS immobilization. The hydrophilicity is an important factor for cell adhesion. Nevertheless, the contact angles of PLLA-ASI and PLLA-ASI-RGDS films are close, so the main reason for the differences in cell attachment is not hydrophilicity but the immobilization of RGDS, which can be recognized by the adhesion receptor on the cell membrane. ${ }^{[25]}$ The recognition of grafted RGDS is more efficient than the promotion of a material's hydrophilicity, which corresponds to the previous study. ${ }^{[26]}$ The rate of attachment of ROS cells to the PLLA-45ASI-RGDS film is obviously the greatest. The above outcome indicates that the increase in grafted RGDS is beneficial for the attachment of ROS cells, which can be achieved with longer ozone treatment time. (a)

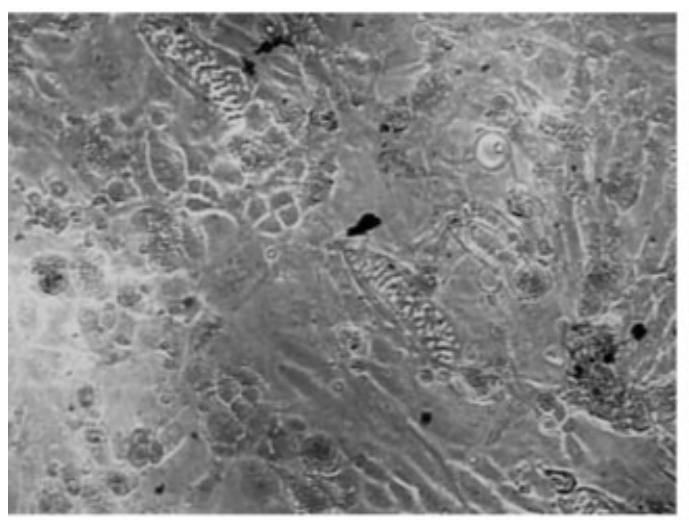

(b)

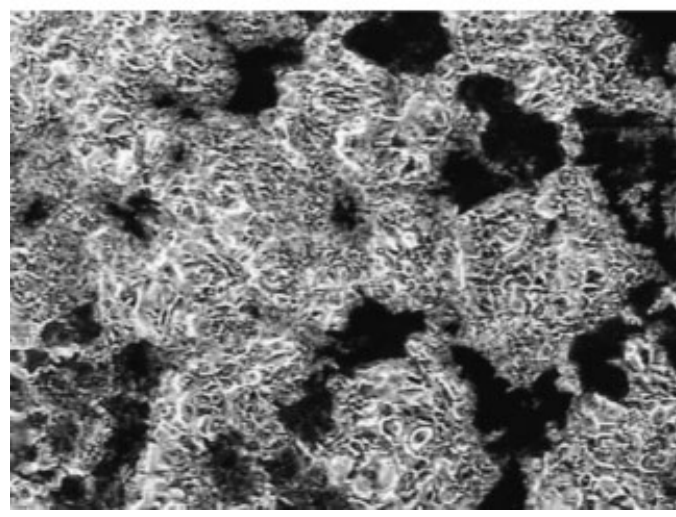

(c)

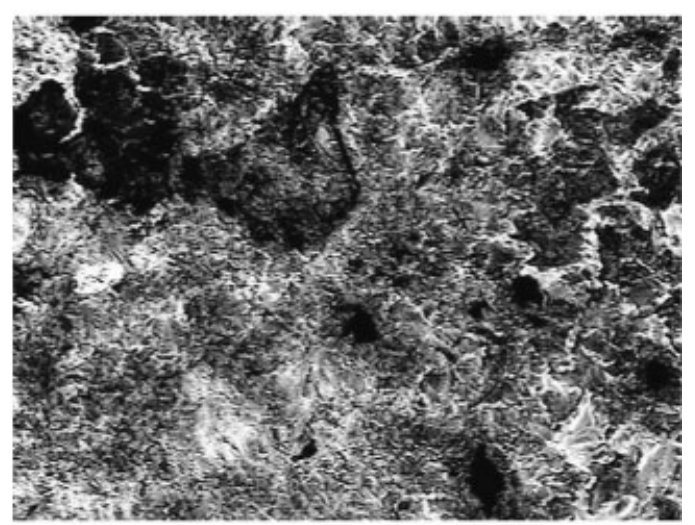

(d)

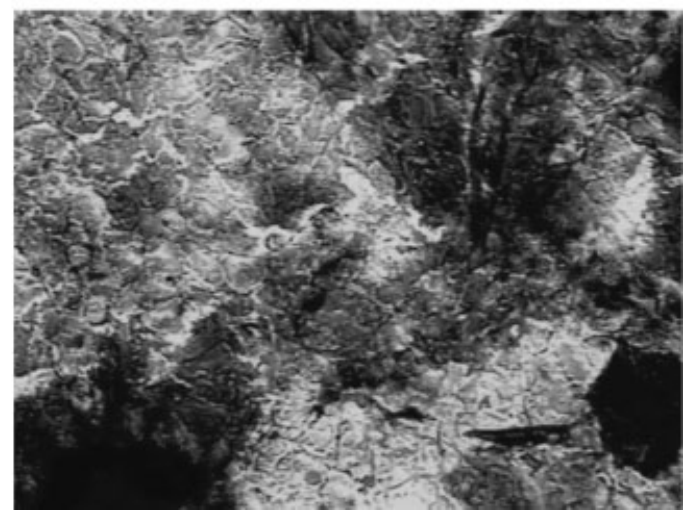

Figure 4. Results of von Kossa staining. The calcium deposits are marked as black or dark brown. ROS cells were cultured on a) PLLA-45ASI film, b) PLLA-15ASI-RGDS film, c) PLLA-30ASI-RGDS films, and d) PLLA-45ASI-RGDS films. The time was 1 week for cell culture and $10 \mathrm{~d}$ for mineralization induction. The size of the pictures is $80 \mu \mathrm{m} \times 60 \mu \mathrm{m}$. For the unmodified PLLA films, it was difficult to reach the confluent state and almost no calcium deposits exist, so the pictures are not shown. 


\section{In Vitro Mineralization}

\section{Assay of Alkaline Phosphatase (ALPase) Activity and DNA}

The effects of ASI and RGDS immobilization on ALPase activity of ROS cells are described in Figure 3. The continued expression and reasonable value of the early osteoblastic markers, ALPase activity, indicate the maintenance of the osteoblastic phenotype by ROS cells attached to the modified PLLA films, which is not affected by the existence of ASI. Generally speaking, the longer the culture takes, the higher the ALPase activities noted. From Figure 3, the ALPase activity is basically dependent on the concentration of immobilized RGDS. The ROS cells express a higher degree of ALPase activity when cultured on the PLLA films with a higher amount of grafted RGDS. However, the ALPase activity of ROS cells cultured with PLLA-45ASI-RGDS films is almost the same as those cultured with PLLA-30ASI-RGDS films for $7 \mathrm{~d}$. That is, although the cell adhesion is greatly accelerated when cultured with PLLA-45ASI-RGDS, the phenotype expression

(a)

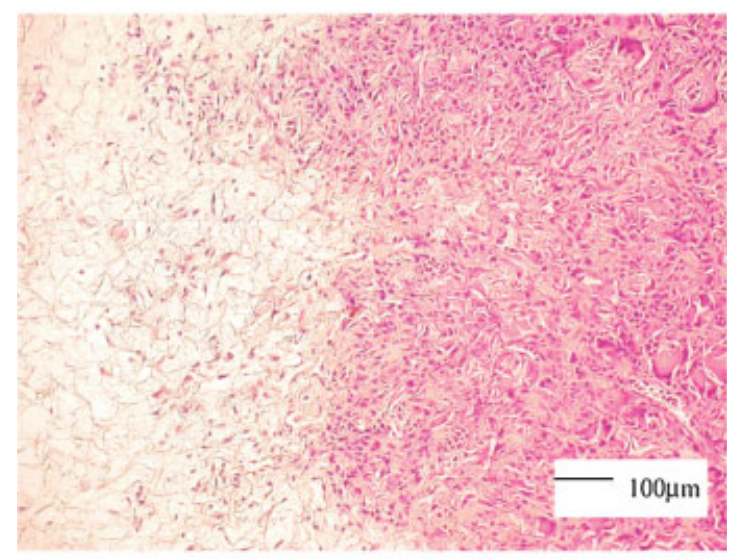

(b)

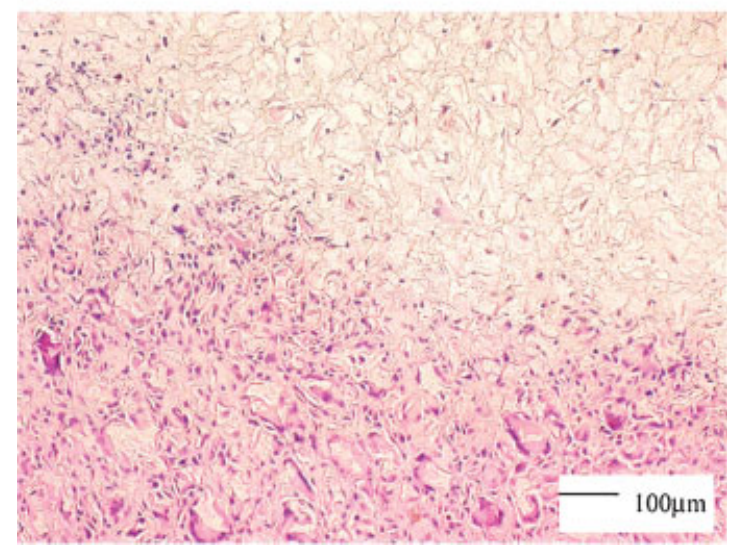

Figure 5. Hematoxylin and eosin stain of unmodified PLLA (a) and PLLA-45ASI-RGDS (b) scaffolds at 2 weeks after implantation. is not promoted to a great extent. A possible reason for this is the suppression of osteoblastic phenotypes under high concentration of grafted RGDS, which is thought helpful to cell attachment. Similar phenomena have been reported for smooth muscle cells and fibroblasts cultured on RGD-coated glass surfaces, ${ }^{[37]}$ and the culture of chondrocytes under a high surface density of RGD. ${ }^{[38-40]}$

\section{Calcium Deposition (von Kossa Staining)}

Von Kossa staining was performed to investigate if ROS cells can precede the calcium deposits, the late marker of cell mineralization. Inside the bone-like tissues, deposition of calcium salts occurs, which is stained as dense black spots. From Figure 4, with the same mineralization time, the PLLA-ASI-RGDS films have larger areas of black spots than the PLLA-ASI films. The results indicate that more cells tend to form bone-like tissues with the RGDS immobilization. The evidence suggests that the graft of RGDS by ozone treatment would improve cell mineralization. In addition, the appearance of ASI does not influence the mineralization behavior of ROS cells. A comparison of PLLA-ASI-RGDS films with different times for ozone treatment reveals that there are much more black spots on the PLLA-30ASI-RGDS film than those on the PLLA15ASI-RGDS, and only a little more than those on the PLLA-45ASI-RGDS. The observation agrees well with the results of ALPase activity.

\section{In Vivo Study}

The biocompatibility of PLLA-ASI-RGDS has been confirmed by histological analysis. The sections of rat tissues surrounding the implanted scaffolds, which include pristine PLLA and PLLA-45ASI-RGDS, show similar degrees of slight foreign body reaction and no inflammation reaction (Figure $5 \mathrm{a}$ and b). Since PLLA implants are accepted as being biocompatible, ${ }^{[41-43]}$ the ASI modification in this study is also biocompatible and should be acceptable for most biomedical applications. The main difference revealed by the histological sections is the erosion time of the implants, which can be observed from the completeness of the implanted scaffolds. For unmodified PLLA, the erosion was slight 4 weeks after the implantation; however, PLLA-45ASI-RGDS scaffolds began to collapse 2-3 weeks after the implantation. The difference in erosion rates is a result of the promotion in cell affinity by the modification processes, which had been revealed by the in vitro experiments.

\section{Conclusion}

A PLLA-ASI-RGDS copolymer is successfully synthesized through thermally induced grafting with ozone activation, 
by which peroxides can easily be introduced onto the polymer chains of PLLA. The results from contact angle measurement and elemental analysis verify the modification, and the concentration of grafted RGDS is proven to be in the effective order by HPLC. The peroxide concentration is controlled by the treatment time, which can be used to adjust the surface concentration of grafted RGDS. The results indicate that the addition of ASI is significantly helpful for the improvement of the grafting efficiency. From the in vitro experiments, the graft of RGDS can promote the cell affinity of PLLA, and the addition of ASI does not affect the attachment, proliferation, and osteogenesis of ROS cells. The good biocompatibility of ASI-modified PLLA is evidenced in the in vivo study. It implies that the modification process in this research possesses high potential for biomedical materials.

Acknowledgements: The authors sincerely thank the following: the National Science Council, Taiwan for their financial support (94-2218-E-011-017-). Ms. Su-Jen Ji (at the Advanced Instrument Center, National Taiwan University, Taipei) for help with performing the SEM analysis, and Prof. Ta-Hsiu Liao (Graduate Institute of Biochemistry and Molecularbiology, National Taiwan University, Taipei) for assistance in performing amino acid analysis.

Received: November 1, 2006; Revised: January 17, 2007; Accepted: January 17, 2007; DOI: 10.1002/mabi.200600241

Keywords: ASI; biocompatability; ozone oxidation; PLLA; RGDS; ROS cells; surfaces

[1] A. G. A Coombes, E. Verderio, B. Shaw, X. Li, M. Griffin, S. Downes, Biomaterials 2002, 23, 2113.

[2] C. R. Chu, R. D. Coutts, M. Yoshioka, F. L. Harwood, A. Z. Monosov, D. Amiel, J. Biomed. Mater. Res. 1995, 29,1147.

[3] Z. Ma, C. Gao, Y. Gong, J. Shen, Biomaterials 2005, 26, 1253.

[4] J. M. Gao, L. Niklason, R. Langer, J. Biomed. Mater. Res. 1998, $42,417$.

[5] J. K. Sherwood, S. L. Riley, R. Palazzolo, S. C. Brown, D. C. Monkhouse, M. Coates, L. G. Griffith, L. K. Landeen, A. Ratcliffe, Biomaterials 2002, 23, 4739.

[6] V. Sluzky, J. A. Tamada, A. M. Klibanov, R. Langer, Proc. Natl. Acad. Sci. 1991, 88, 9377.

[7] N. Krasteva, T. Groth, F. Fey-Lamprecht, G. Altankov, J. Biomater. Sci. Polym. Ed. 2001, 12, 613.

[8] V. Guenard, R. F. Valentini, P. Aebischer, Biomaterials 1991, 12, 259.

[9] V. M. Hiljanen, P. Varpomaa, J. Seppala, P. Tormala, Macromol. Chem. Phys. 1996, 197, 1503.

[10] Y. B. Zhu, C. Y. Gao, X. Y. Liu, J. C. Shen, Biomacromoles 2002, 3, 1312 .
[11] F. E. Black, M. Hartshorne, M. C. Davies, C. I. Roberts, S. J. B. Tendler, P. M. Williams, K. M. Shakesheff, Langmuir 1999, 15, 3157.

[12] J. J. Yoona, S. H. Songa, D. S. Leeb, T. G. Park, Biomaterials 2004, 25, 5613

[13] H. Suh, Y. S. Hwang, J. E. Lee, C. D. Han, J. C. Park, Biomaterials 2001, 22, 219.

[14] C. F. L. Chu, A. Lu, M. Liszkowski, R. Sipehia, Biochim. Biophys. Acta. Gen. Subj. 1999, 1472, 479.

[15] Z. W. Ma, C. Y. Gao, Y. H. Gong, J. C. Shen, Biomaterials 2003, 24, 3725 .

[16] Z. W. Ma, C. Y. Gao, J. C. Shen, J. Biomater. Sci. Polym. Ed. 2003, $14,13$.

[17] S. Zhang, Z. Hou, K. E. Gonsalves, J. Polym. Sci., Part A: Polym. Chem. 1996, 34, 2737.

[18] A. H. He, C. C. Han, G. S. Yang, Polymer 2004, 45, 8231.

[19] J. Yang, Y. Q. Wan, C. F. Tu, Q. Cai, J. Z. Bei, S. G. Wang, Polym. Int. 2003, 52, 1892.

[20] H. Suh, M. J. Song, M. Ohata, Y. B. Kang, S. Tsutsumi, Tissue Eng. 2003, 9, 635.

[21] M. H. Ho, L. T. Hou, C. Y. Tu, H. J. Hsieh, J. Y. Lai, W. J. Chen, D. M. Wang, Macromol. Biosci. 2006, 6, 90.

[22] E. T. Kang, K. G. Neoh, X. Zhang, K. L. Tan, D. J. Liaw, Surf. Interface Anal. 1996, 24, 51.

[23] L. Ying, G. Zhai, A. Y. Winata, E. T. Kang, K. G. Neoh, J. Colloid. Interface Sci. 2003, 265, 396.

[24] E. Ruoslahti, M. D. Pierschbacher, Science 1987, 238, 491.

[25] M. H. Ho, D. M. Wang, H. J. Hsieh, H. C. Liu, T. Y. Hsien, J. Y. Lai, L. T. Hou, Biomaterials 2005, 26, 3197.

[26] P. Wang, K. L. Tan, E. T. Kang, K. G. Neoh, J. Mater. Chem. 2001, $11,783$.

[27] L. T. Hou, J. A. Yager, J. Oral Pathol. Med. 1995, 24, 97.

[28] S. J. Xiao, S. Brunner, M. Wieland, J. Phys. Chem. B 2004, 108, 16508.

[29] A. Rezania, K. E. Healy, J. Ortho. Res. 1999, 17, 615.

[30] A. Rezania, K. E. Healy, Biotechnol. Prog. 1999, 15, 19.

[31] D. A. Barrera, E. Zylstra, P. T. Lansbury, R. Langer, Macromolecules 1995, 28, 425.

[32] S. M. Li, I. Rashkov, J. L. Espartero, N. Manolova, M. Vert, Macromolecules 1996, 29, 57.

[33] R. A. Quirk, W. C. Chan, M. C. Davies, S. J. B. Tendler, K. M. Shakesheff, Biomaterials 2001, 22, 865.

[34] D. C. Alonzo, J. S. Hrkach, N. N. Gao, I. M. Johnson, U. B. Pajvani, S. M. Cannizzaro, R. Langer, J. Biomed. Mater. Res. 1997, 35, 513.

[35] D. A. Barrera, E. Zylstra, P. T. Lansbury, R. Langer, J. Am. Chem. Soc. 1993, 115, 11010.

[36] K. Kim, M. Yu, X. H. Zong, J. Chiu, D. F. Fang, Y. S. Seo, B. S. Hsiao, B. Chu, M. Hadjiargyrou, Biomaterials 2003, 24, 4977.

[37] J. H. Jang, Y. Ku, C. P. Chung, S. J. Heo, Biotechnol. Lett. 2002, 24, 1659.

[38] T. Yasuda, K. Shimizu, Y. Nakagawa, H. Ishikawa, H. Nishihara, T. Nakamura, J. Bone Mineral. Res. 1996, 11, 1430.

[39] S. Ohno, T. Doi, S. Tsutsumi, Y. Okada, K. Yoneno, Y. Kato, K. Tanne, Biochim. Biophys. Acta. Gen. Subj. 2004, 422, 161.

[40] C. S. Chen, M. Mrksich, S. Huang, G. M. Whitesides, D. E. Ingber, Science 1997, 276, 1425. 